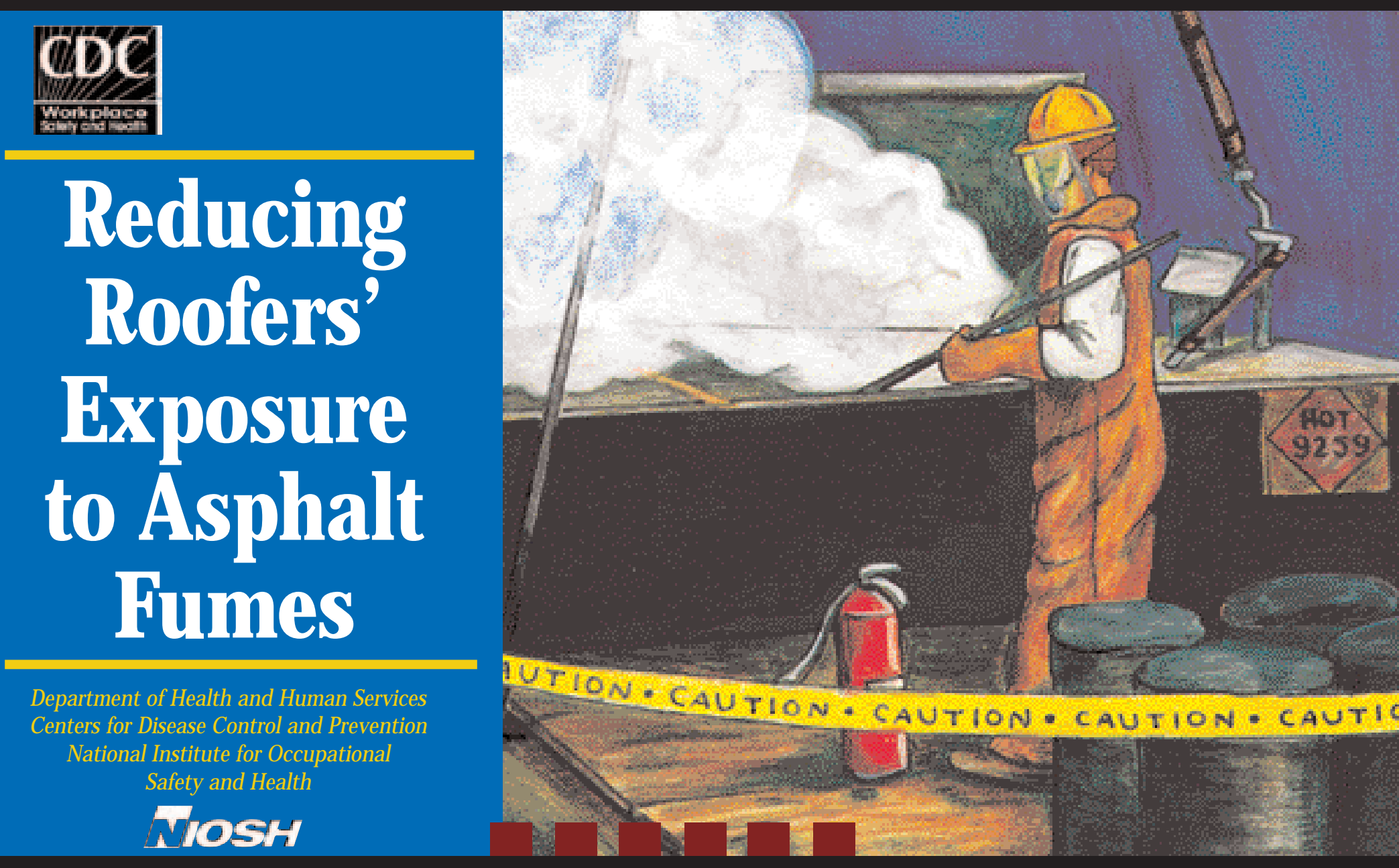




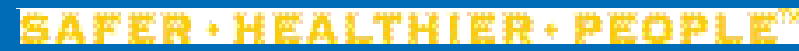




\section{Reducing Roofers' Exposure to Asphalt Fumes}

Department of Health and Human Services

Centers for Disease Control and Prevention

National Institute for Occupational Safety and Health

August 2003 
This document is in the public domain and may be freely copied or reprinted. Disclaimer

Mention of any company or product does not constitute endorsement by NIOSH.

\section{Ordering Information}

To receive documents or more information about occupational safety and health topics, contact the National Institute for Occupational Safety and Health (NIOSH) at

NIOSH - Publications Dissemination

4676 Columbia Parkway

Cincinnati, OH 45226-1998

Telephone: 1-800-35-NIOSH (1-800-356-4674)

Fax: 513-533-8573

E-mail: pubstaft@cdc.gov

or visit the NIOSH Web site at www.cdc.gov/ niosh

DHHS (NIOSH) Publication No. 2003-107

August 2003 


\section{Contents}

口

Introduction $\ldots \ldots \ldots \ldots \ldots \ldots \ldots \ldots \ldots \ldots \ldots$

What steps should contractors take before starting work? 3

1. Assign a competent person ............... 3

2. Assure that workers have been properly educated ...... 3

3. Plan the work site . . . . . . . . . . . . . . . . . . . . . 4

What safe work practices should roofers use? . . . . . . . . 5

1 Manage the kettle ................ 5

Use the proper equipment $\ldots \ldots \ldots \ldots \ldots \ldots \ldots$

Follow safe procedures ................. 5

Maintain asphalt temperature . . . . . . . . . . . 6

2. Safely apply hot asphalt to the roof $\ldots \ldots \ldots \ldots \ldots$

What personal protective equipment should roofers wear? 9 What personal hygiene practices should roofers follow? . . 10 More Information $\ldots \ldots \ldots \ldots \ldots \ldots \ldots \ldots \ldots$ Appendix A. Respirators . . . . . . . . . . . . . . . . . . . . . . . 12

Appendix B. OSHA Regulations that Apply to Roofing . . . . 13 
This safety guide was prepared by a working group from the National Institute for Occupational Safety and Health (NIOSH) with help from the following partners:

- United Union of Roofers, Waterproofers, and Allied Workers (UURWAW)

- The National Roofing Contractors Association (NRCA)

- The Asphalt Roofing Manufacturers Association (ARMA)

- The Asphalt Institute (AI)

\section{NIOSH working group members:}

- Ralph Zumwalde

- Harry Watson

- J oann Wess

- Anne Hamilton

- J erry Flesch

- Pauline Elliott

This guide may be used with the NIOSH technical document Asphalt Fume Exposures During the Application of Hot A sphalt to Roofs (DHHS [NIOSH] Pub. No. 2003-112) and the NRCA video Asphalt Fume Exposure: Keep it Down, prepared in cooperation with other asphalt industry partners listed above. To obtain a copy of the video, call the National Roofing Contractors Association at 847-299-9070, or e-mail them at NRCA@ nrca.net. 


\section{Introduction}

This guide is for roofers and contractors who work with hot asphalt on roofs. The guide lists steps for reducing exposure to asphalt fumes.

Roofers exposed to asphalt fumes may experience the following health effects:

- headache

- eye, nose, throat, and skin irritation

- nausea

- fatigue

- drowsiness

These effects appear to be mild and transient.

According to some studies, roofers also have an increased risk of lung cancer. But researchers are not sure whether this risk is caused by exposure to asphalt fumes or to other hazards such as smoking, coal tar, or asbestos. In light of this possible health risk and the irritation effects associated with hot asphalt work, it makes sense to take steps to control exposures while government, industry, labor, and independent researchers continue to study these health concerns. 
NIOSH is working together with industry and labor representatives to find methods that will significantly reduce asphalt fume exposures for roofers and contractors. Efforts are under way to identify new engineering controls and to test their effectiveness in reducing fume exposures at the kettle. To date, studies have shown that the use of fume-suppressing roofing asphalts can reduce fume exposure at the kettle. As these studies are completed, appropriate recommendations will be developed and disseminated. 
Choose a person to be responsible for the safety and health of the crew.

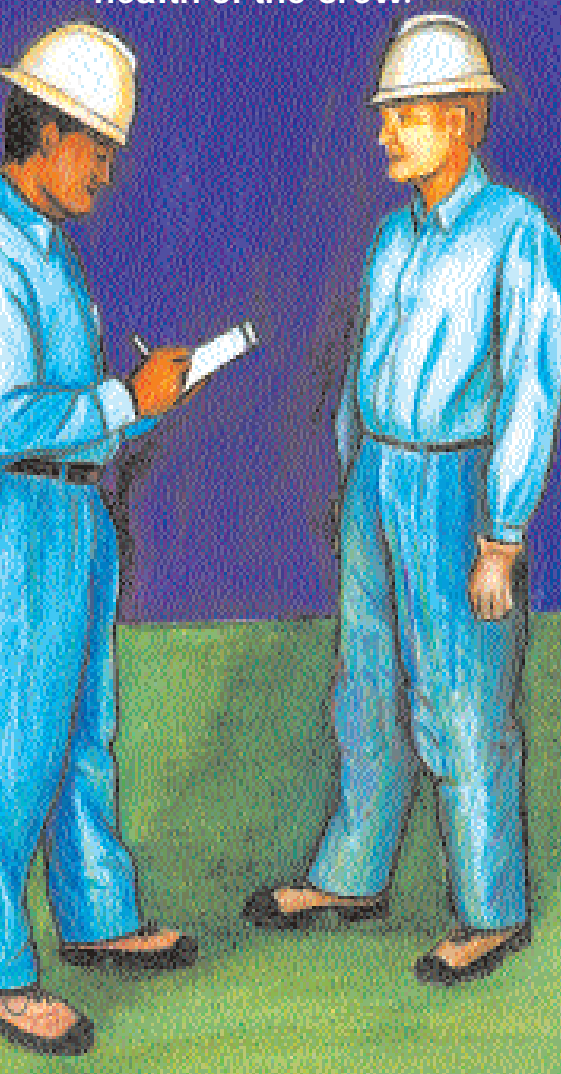

\section{What Steps Should Contractors Take Before Starting Work?}

1 Assign a competent person to be responsible for safety and health on the job. This person, usually the superintendent or the foreman, will have knowledge about roofing hazards and the authority to take prompt corrective measures to eliminate unsafe acts or unsafe conditions on the job.

2. Assure that workers have been properly educated about the hazards of applying hot asphalt and trained in the use of safe work practices as well as the use of the personal protective equipment (PPE) needed to reduce exposures to asphalt fumes. 


\section{Plan each work site before work begins to reduce asphalt} fume exposures for workers and building occupants.

- Consider using a tanker to supply asphalt to the kettle or directly to the rooftop.

- If kettles must be used, place them where the operator and workers will be least exposed to the fumes. Keep the kettle away from air intakes, doors, and windows.

- Consult with building owners about how to minimize concerns from occupants about asphalt fumes. Consider notifying occupants before the job begins. Discuss with building owners whether air intake systems should be turned off and whether all applicable building air intake vents should be closed or covered.

- Consider scheduling work during off hours for commercial buildings and during school or work hours for private residences.

- Consider using roofing equipment and accessories that have lids to reduce exposure to fumes.

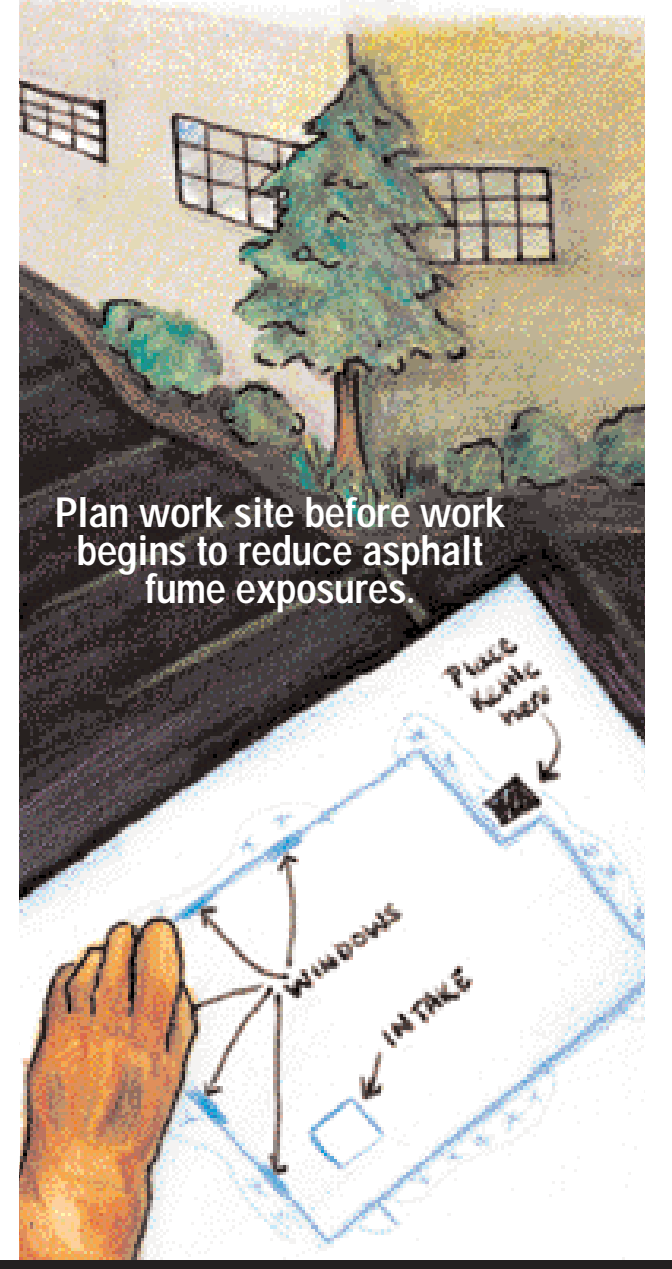




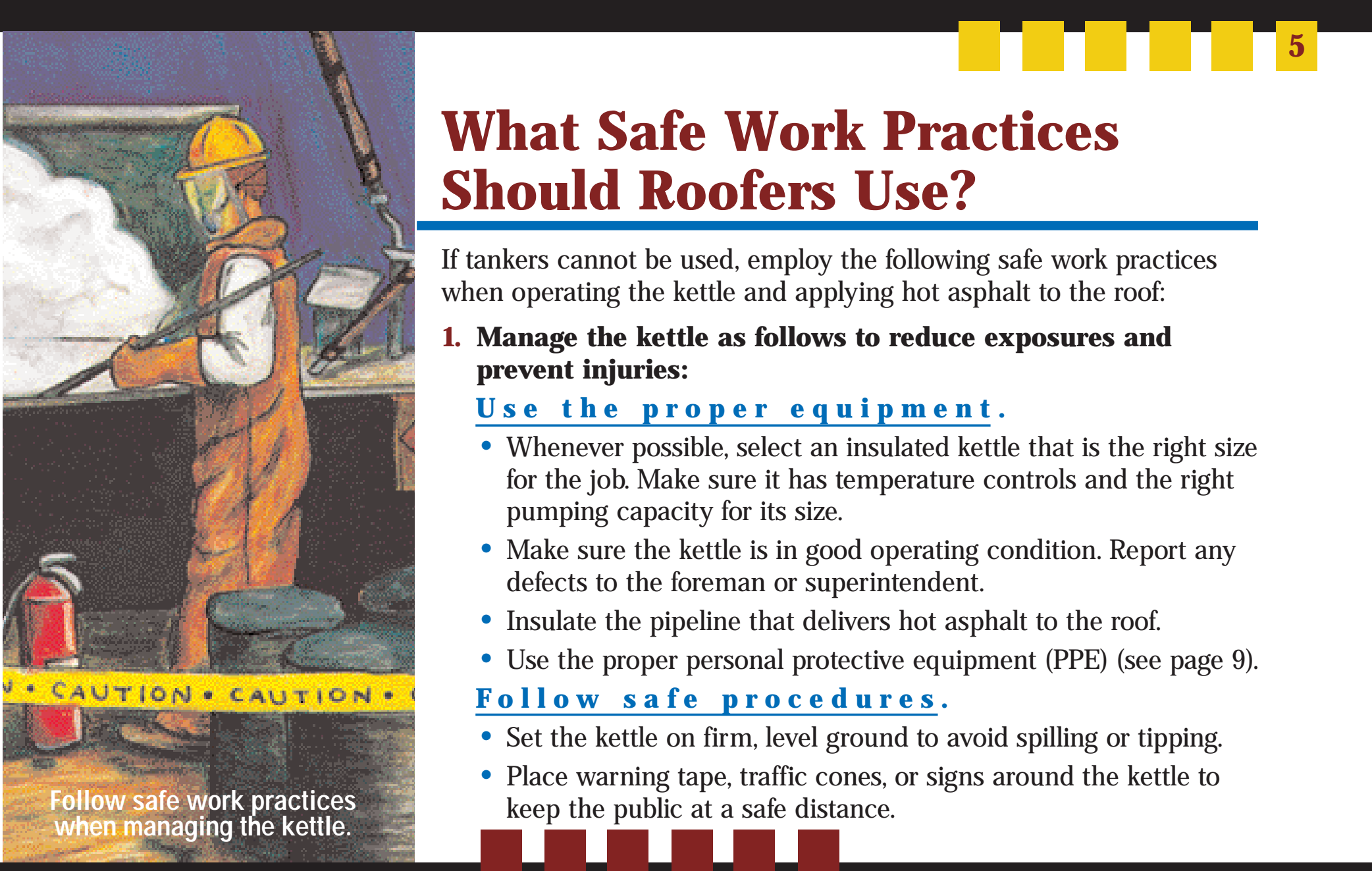


- Keep a fully charged ABC-type fire extinguisher near the kettle. Make sure all workers know how to use it.

- Reduce the number of times the lid is opened. Fill the kettle to capacity when reloading and check the temperature, stir, and skim at the same time.

- Pre-chop the asphalt into pieces that can be easily handled and melted.

- Consider using fume-suppressing asphalts.

Maintain asphalt temperature.

Take the following steps to maintain proper asphalt temperature and reduce exposure to asphalt fumes:

- Find the equiviscous temperature (EVT) and flash point of the asphalt on the keg package or bill of lading.

- To begin, set the kettle temperature at the EVT plus $50^{\circ} \mathrm{F}$.

- Communicate with the rooftop crew as they periodically measure the asphalt temperature in the mop bucket at the application point.

- Adjust the kettle temperature to maintain proper temperature (the EVT plus or minus $25^{\circ} \mathrm{F}$ ).

- ALWAYS keep the kettle temperature at least $25^{\circ} \mathrm{F}$ below the flash point to avoid fires and explosions! 
- Read the temperature after skimming, stirring, loading, or transferring the asphalt.

- Use a hand-held or infrared thermometer to get an accurate reading of the temperature of the hot asphalt.

- Do not point the infrared thermometer gun at anyone's face or eyes! This could result in damage to the eyes!

2. Safely apply hot asphalt to the roof. Use the following work practices:

- Keep lids closed on rooftop equipment and accessories used to transport and apply hot asphalt.

- Stay out of the fume cloud whenever possible.

- Consider using a fan to reduce exposures in certain work areas:

- Make sure the fan blows air away from workers.

- Keep all cords and fans out of the workers' walking paths.

- Make sure that electrical connections for fans are grounded. 
- If buckets are used, take the following precautions:

- Use buckets with half lids.

- Fill buckets only three-fourths full.

- Carry buckets on the down slope of the roof.

- Twist mops to unstick them from buckets- do not pull them.

- Twist buckets to unstick them from the roof.

- Minimize time spent on your knees working with hot asphalt, since exposures may be higher when you are closer to the fumes. Use long-handled tools whenever possible.

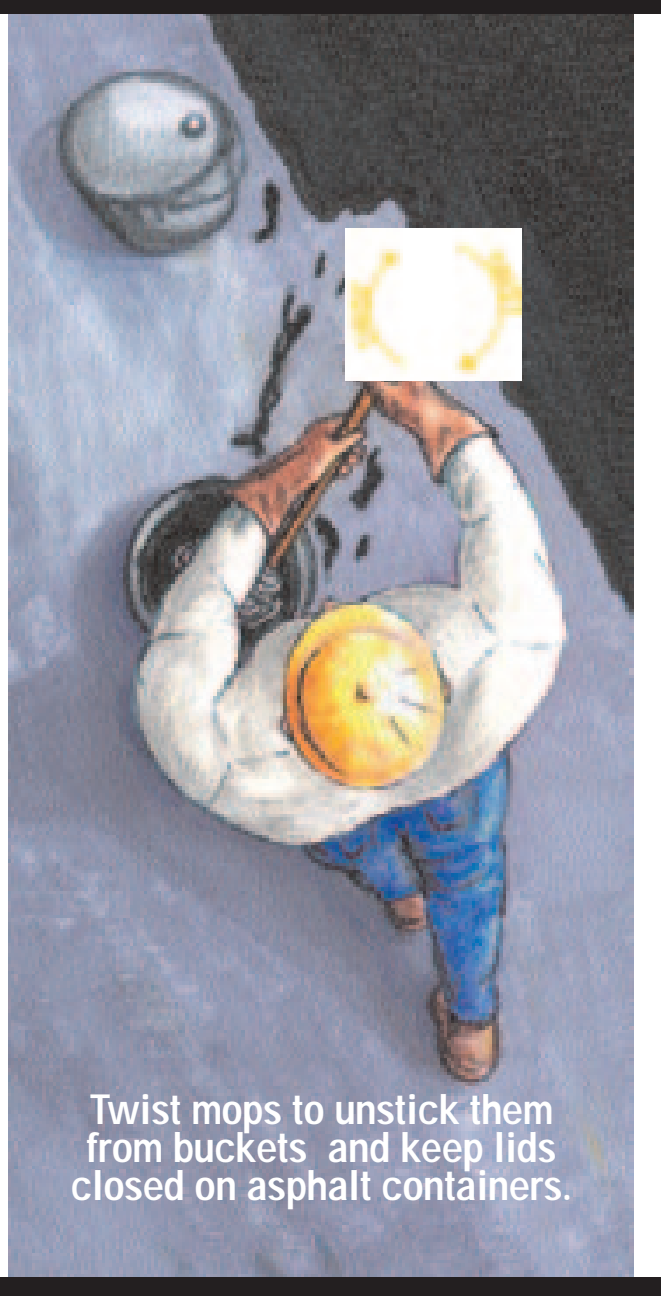




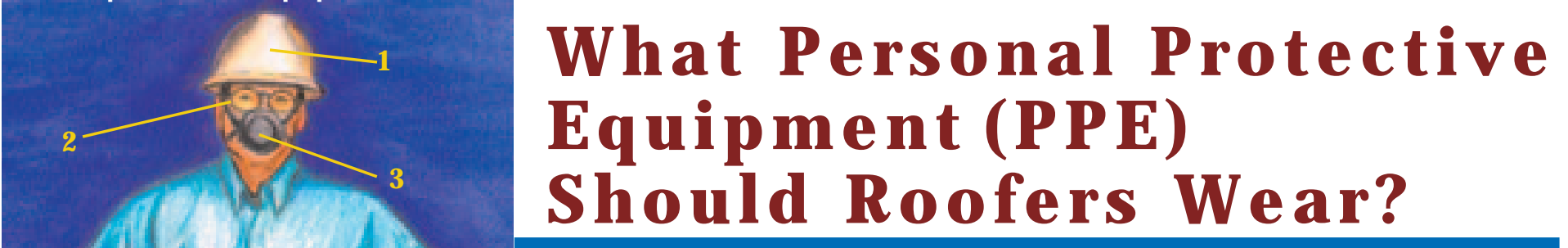

Roofers should wear the following types of PPE to minimize the risk of burns and breathing asphalt fumes:

1. Hard hat (for kettlemen)

2. Goggles or safety glasses with side shields (use a full-faceshield for operating the kettle)

3. Respirators when necessary (see guide in Appendix A on selection and use of respirators)

4. Cotton shirt with long sleeves

5. Leather or heat-resistant gloves that fit tightly around the wrists

6. Long pants with no cuffs

7. Nonskid shoes or boots with 6 -inch leather uppers 
What Personal Hygiene Practices Should Roofers Follow?

Personal hygiene is important to protect workers from a variety of different chemical exposures that are common in roofing work. Employers should provide workers with clean water, soap or other safe cleaners. Workers should follow these personal hygiene practices:

- Wash hands before eating and before leaving the work site. Use soap or other safe cleaners-do not use gasoline or other chemicals.

- Eat lunch away from asphalt fumes. Sit where the wind will blow fumes away from you.

- Shower after work as soon as possible.

- Change work clothes before going home to keep asphalt and solvents out of your car and home.

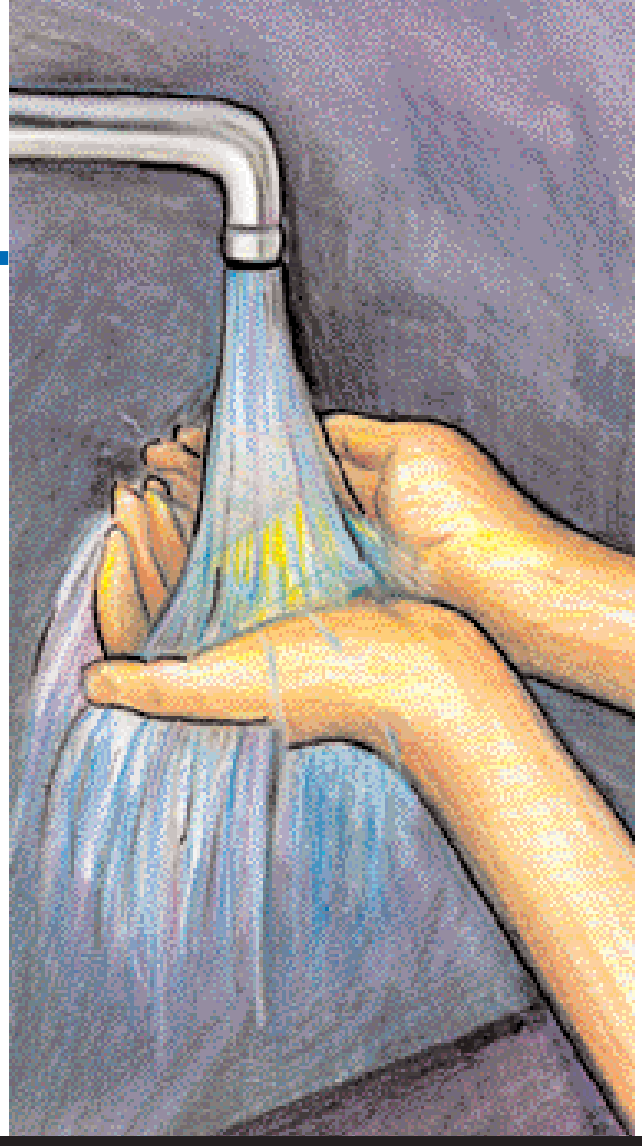




\section{More Information}

For more information about possible health effects from exposure to asphalt and about the selection of appropriate respiratory protection, see the following publications:*

NIOSH [1987]. NIOSH respirator decision logic. Cincinnati, OH: U.S. Department of Health and Human Services, Centers for Disease Control, National Institute for Occupational Safety and Health, DHHS (NIOSH) Publication No. 87-108.

NIOSH [1996]. NIOSH guide to the selection and use of particulate respirators certified under 42 CFR 84. Cincinnati, OH: U.S. Department of Health and Human Services, Public Health Service, Centers for Disease Control and Prevention, National Institute for Occupational Safety and Health, DHHS (NIOSH) Publication No. 96-101.

NIOSH [2000]. Health effects of occupational exposure to asphalt. U.S. Department of Health and Human Services, Public Health Service, Centers for Disease Control and Prevention, National Institute for Occupational Safety and Health, DHHS (NIOSH) Publication No. 2001-110.

*To receive free single copies of $\mathrm{NIOSH}$ publications, contact NIOSH as follows:

Telephone: 1-800-35-NIOSH (1-800-356-4674) or visit the NIOSH Web site at Fax: 513-533-8573 www.cdc.gov/ niosh

E-mail: pubstaft@cdc.gov 


\section{Appendix A-Respirators}

Respiratory protection may be needed if available engineering controls and work practices are ineffective in keeping asphalt fume exposures below the NIOSH recommended exposure limit of $5 \mathrm{mg} / \mathrm{m}^{3}$ (measured as a 15-min ceiling) or applicable State or Federal standards. However, because respirator use can introduce significant new safety hazards in roofing work, respirator use should be the last resort for controlling exposures.

If respirators are required at the work site, the employer or contractor must make sure that they are $\mathrm{NIOSH}$-approved and that all applicable OSHA regulations that apply to respirator programs are followed. Important elements of these OSH A regulations are as follows:

- An evaluation of the worker's ability to perform the work while wearing a respirator

- Regular training of workers

- Periodic environmental monitoring

- Respirator fit-testing, maintenance, inspection, cleaning, and storage

- Periodic changing of cartridges and testing for service life

No NIOSH -approved respirator filter cartridge or canister exists specifically for asphalt fumes. But the respirators listed below will reduce exposures:

- Any half-facepiece, air-purifying respirator equipped with a combination R100 or P100 filter and an OV (organic vapor) cartridge

- Any powered, air-purifying respirator with hood, helmet, or loose-fitting facepiece equipped with a combination HEPA and OV cartridge

Note: The appropriate respirator filter is R100, P100, or HEPA as listed under 42 CFR 84 . The appropriate OV cartridge or canister should contain a charcoal sorbent. This type of protection can also be used during the tearing off of old roofs-when workers may be exposed to dust containing coal tar. Other types of respirators provide better protection and may be required under certain conditions, such as work in confined spaces. See NIOSH Respirator Decision Logic (DHHS [NIOSH] Publication No. 87-108). 


\section{Appendix B-OSHA Regulations that Apply to Roofing}

29 CFR 1926.20

29 CFR 1926.21

29 CFR 1926.23

29 CFR 1926.25

29 CFR 1926.27

29 CFR 1926.55

29 CFR 1926.59

29 CFR 1926.95

29 CFR 1926.96

29 CFR 1926.100

29 CFR 1926.101

29 CFR 1926.102

29 CFR 1910.134

29 CFR 1926.103

29 CFR 1926.104

29 CFR 1926.105

29 CFR 1926.150-155

29 CFR 1926.500-503

29 CFR 1926.1101

29 CFR 1926.1102
General safety and health provisions

Safety training and education

First aid and medical attention

Housekeeping

Sanitation

Exposure limits for chemicals, fumes, mists

Hazard communication

Personal protection equipment

Foot protection

Head protection

Hearing protection

Eye and face protection

Respiratory protection

Respiratory protection

Safety belts, lifelines and lanyards

Safety nets

Fire Protection and Prevention

Fall protection

Asbestos

Coal tar pitch volatiles 
Department of Health and Human Services Centers for Disease Control and Prevention National Institute for Occupational Safety and Health 4676 Columbia Parkway Cincinnati, OH 45226-1998

National Institute for

Occupational Safety and Health

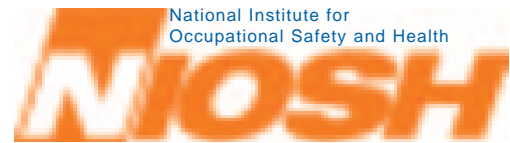

Delivering on the Nation's Promise: Safety and health at work for all people through research and prevention

DHHS (NIOSH) Publication No. 2003-107 